\title{
A Correlative Study between Depression and Academic Achievement of Students with Physical Challenges Studying through Non-Formal System of Education
}

\author{
Munawar Malik ${ }^{1}$
}

\begin{abstract}
Depression known as mood disorder is a low mood state that presents at a sustained level and confines activities of a person in daily routine. It can affect thoughts, behaviors, feelings of physical well-being, social, occupational, achievements as well as personal and interpersonal skills etc. Being one of the common ailments, persons with physical challenges may also fall a victim to it and thus affect their crucial elements of life as mentioned. The primary objective of this study was to find a relationship that may exist in depression and academic achievement in students studying through non-formal system of education, i.e. distance education. The current study had a descriptive design and was correlative in nature. Students with physical challenges studying through nonformal education comprised the population. The sample of the study subsumed 100 students randomly selected and was later subjected to further testing for depression. The tool of the study comprised a purpose built inventory for measuring depression that was validated and checked for reliability beforehand. The findings of the study revealed that there is negative correlation between depression and academic achievement of depressed physically challenged students studying through non-formal educational system. Recommendations included an engagement of students with physical challenges in a more formal and traditional approach of education, formal assessment at the time of registration in order to identify individual needs, capitalizing human interaction through group activities, use of educational technology, counseling and other extracurricular opportunities leading to participatory and shared experience among students.
\end{abstract}

Keywords: Depression, Physical Disabilities, Academic Achievement

\section{Introduction}

American Psychiatric Association defines depression as, "a common and serious medical illness that negatively affects what a person feels, the way he/she think and how he/she acts". American Psychiatric Association expands this

\footnotetext{
${ }^{1}$ Assistant Professor, Department of Special Education, University of the Punjab, Lahore Email: munawar.dse@pu.edu.pk/munmalik@yahoo.com
} 
definition slightly by stating that depression is more than just sadness. People with depression may experience a lack of interest and pleasure in daily activities, significant weight loss or gain, insomnia or excessive sleeping, lack of energy, inability to concentrate, feelings of worthlessness or excessive guilt and recurrent thoughts of death or suicide. Depression may be caused by one or a combination of factors including biological, psychological, genetic and environmental factors. According to World Health Association (WHO), depression is the most common illness worldwide. Among other common tools for quantifying depression, Beck's Depression Inventory (BDI) is a 21-item; self-report rating inventory that measures characteristic attitudes and symptoms of depression (Beck, Ward, Mendelson, Mock \& Erbaugh, 1961).

With ever increasing population of the world the disability is on a rise. Although, the advent of newer medicine and technology has reduced the likelihood of disability on one hand, the blooming war technology stands a major concern. Natural disabilities and war afflicted ones if counted together have a different story to share. According to U.S. Census Bureau (2011), out of seven billion living across the globe 15 percent of the population strive with disabling conditions. Among the disabled are persons with physical challenges who may suffer at the hands of physical limitation posed by paralysis, amputations, congenital deformities, etc. The most recent census in Pakistan has reported around 2.49 percent people suffering from one form of disability or the other. As per World Health Organization (WHO), "people with physical disabilities are among the most marginalized groups in the world.... People with disabilities have poorer health outcomes, lower education achievements, less economic participation and higher rates of poverty than people without disabilities" (WHO, 2011).

A relationship between physical disabilities and depression exists and has been reported generously in literature. Person with physical challenges may fail to develop specific bodily functions, whether of movements, sensations, coordination or speech but excluding mental impairment. While the challenge in terms of physical abilities is coupled with depression other psychological issues also start to interfere which may have greater negative impacts on their daily routine activities. While for students with such capacities, the respective areas of educational or academic achievements may also get affected.

Non-formal Education is a general term for education that depicts a learning experience other than a formal face to face engagement and in absence of a structured environment. Informal Education encompasses student's interest within a curriculum but is not limited to a particular setting. It works through conversation, and the exploration and enlargement of experience. With limited 
physical abilities, maneuvering skills and limitations the students with physical disabilities face additional challenges in terms of accessibility and transportation. These barriers at times are so grave that such students may opt for other educational options that may include distance education, non-formal or informal education. Students with physical disabilities getting education through informal educational may also become victim of depression. The current study was designed to establish evidence about depression in the subject population and prospective impacts of the same in terms of academic achievement.

\subsection{Objectives of Study}

The objectives of the study included to:

1. Find incidence of depression in students with physical disabilities.

2. Explore a relationship between respective level of depression and academic achievement of students with physical challenges studying through nonformal education system.

\section{Literature Review}

The respective system in terms of formal and informal education practices have a wide array of presumptions, practices and operating procedures. While the formal traditional classrooms offer face to face instruction with the teacher and the learners, the distance learning practice leaves a significant gap between these counterparts. Highly dependent on assignments and self-practice, the informal education approach may leave the learners in lurch thus increasing their anxiety. In this particular focus O'Reegan (2003), after interviewing 11 students of online courses reported that students feel anxiety due to lack of clear instructions, not knowing what to do and having to find out what to do. Keeping in view the above discussion it seems predominantly essential that a study of this sort should look for possible impacts of non-formal systems that could depict the challenges of a student with physical disabilities.

The emotional wellbeing has remained a significant predictor in terms of academic gains. Considering the same a lot has been offered in a more formal education system with slogans like "healthy bodies- healthy mind". Offerings of this sort fall significantly short in non-formal systems thus the qualitative aspects of learning may be comprised. Emotional wellbeing of a person ensures success in any endeavor that is attempted. Recent studies have highlighted that emotions are critically involved in the learning process either inhibiting or enhancing it (Hara \& Kling, 1999; Hara \& Kling, 2003; O'Reegan, 2003; Rovai \& Wighting, 2005). The role of emotions is critical in adult learning as they are closely linked with the construction of meaning and knowledge (Dirkx, 2001; Shuck et al., 2007). Students with disabilities have been reported to suffer in higher education 
in particular and have been notified as sufferers as far as the academic wellbeing is concerned. A similar study was conducted by Riddell, Wilson \& Tinklin (2002) indicates that even when disabled students start out with comparable qualifications to other students in the same university, they tend to encounter more barriers to learning and to achieve lower outcomes in terms of final degree classification. Riddell also identified an unplanned and ill harmonized support system for students with disabilities. This itself reflects upon the need to find challenges that are faced by students with special needs in a typical scenario that is offered in Pakistan.

The study of this intent holds its significance as it will help in identifying benchmarks which need to be focused for a student with physical challenges while opting from a variety of options for studying, i.e. formal (traditional) nonformal (distance education), etc. Since, depression being a common agenda in terms of ordinary and special students, it is vital that we could establish respective incidence in a typical student of Pakistani origin and its respective impacts on students with physical limitation. Since students with physical limitations have additional challenges when it comes to learning and teaching styles etc., a discussion is warranted particularly for non-formal offerings for this group of learners. Literature reflects upon a large number of students who whereby their disabilities have been prevented for aspiring further education. A study carried out by Disability Rights Commission (DRC, 2002) indicated a huge number of 30 percent among the disabled who by the virtue of their impairments could not proceed for further education. Among the significant factors reported by DRC included support, transport and accommodation, etc. As reported by Riddell, Tinklin \& Wilson (2005) disabled students' participation in higher education is generally reported to be low. It is hoped that the findings of this particular study will pave way for further discussion to restructure the non-formal system to the needs of such students and further the short comings of such a system will be highlighted in the process.

\subsection{Research Design}

\section{Research Methodology}

The study was a descriptive and correlative research in nature and was based on survey design. While the instrumental use will identify and classify the incidence and type of depression, the comparison of different levels with the academic performance will establish some sort of relationship that may prevail.

\subsection{Population \& Sample}

In the most recent $6^{\text {th }}$ Population Census (2017), the incidence of disabilities has been reported as $0.48 \%$ which in comparison was $2.38 \%$ in last census (1998). According to Pakistan Bureau of Statistics (2017), the total 
disabled population is $3,286,630$ while in Punjab only the figure is 1,826623 . Out of these huge numbers 20.83 percent falls in the category of Crippled (physically challenged) in Punjab province only.

The population of study included adult students having physical challenges studying in non-formal education (distance education) system at graduate and levels above. The sample comprised 100 students randomly selected representing both genders. The inclusion criterion was delimited to adult students representing both genders with physical challenges enrolled in nonformal education system. Students having multiple disabilities, disabilities other than physical and enrollment in regular education system were excluded.

\subsection{Instrumentation}

In order to establish evidence in terms of depression an inventory was developed that served as an instrument for this study. The tool of the research was divided in two sections; $1^{\text {st }}$ section was designed to get the demographic information of respondents. Further to it the first section also offered to translate the educational achievement of the students during the most recent exams as an academic achievement level, i.e. satisfactory to exceptional performance.

\section{Table 1}

Academic Achievement Scale

\begin{tabular}{ll}
\hline Academic Achievement & Percentage score \\
\hline Low & Below $40 \%$ to minimum pass marks \\
Satisfactory & $41 \%$ to $55 \%$ \\
Medium & $56 \%$ to $70 \%$ \\
Excellent & $71 \%$ to $85 \%$ \\
Exceptional & $86 \%$ to above \\
\hline
\end{tabular}

Second section was an inventory developed by researcher in line with the recommendation of DSM V and literature review. Validation and due piloting revealed a Cronbach's alpha score of 0.837 . The inventory comprised of 22 items pertaining to sleep, hallucination, sadness, self-esteem, fear, confidence and solitude. A three point likert's scale extending from 0-2 was provided to the respondents for respective answers. The lowest possible score for each question was zero while the possible score for each question was 2 so the highest score for the test was 44. While keeping in view the scores from respective respondents a scale was devised to gauge depression which signifies levels of depression and is given below. 
Table 2

Scale to Measure for level of Depression.

\begin{tabular}{ll}
\hline Score & Level of Depression \\
\hline $1-10$ & Normal \\
$11-16$ & Mild depression \\
$17-20$ & Borderline clinical depression \\
$21-30$ & Moderate depression \\
$31-40$ & Severe depression \\
0ver 40 & Extreme depression \\
\hline
\end{tabular}

\subsection{Data Collection}

Data were collected from the sample by subjecting them to the tool developed for the purpose. The researcher visited the respondents and carried out the procedural requirements in person. For the academic performance however, results of the previous exams were asked from the respondents and were interpreted.

\section{Data Analysis and Interpretation}

Data thus collected were analyzed with the help of SPSS. The frequencies were counted and reported by tabulation. Level of depression and academic achievement was analyzed by calculating total score achieved by respondents in response in line with the developed inventory. Descriptive statistics and Pearson correlation were used to analyze and describe data. Question-wise data was represented in the forms of tables followed by their interpretation. On the basis of data analysis findings and conclusions were drawn which have been reported below.

The current research focused on finding out the incidence of depression among physically disabled students and to explore the relation between the level of depression and the academic achievement of the students having physical challenges.

Table 4.1

Level of Depression among Respondents

\begin{tabular}{lccc}
\hline Responses & Frequency & Percent & Cumulative Percent \\
& & & \\
\hline Mild & 5 & 5.0 & 5.0 \\
Borderline/ Depress. & 27 & 27.0 & 32.0 \\
Moderate & 61 & 61.0 & 93.0 \\
Severe & 6 & 6.0 & 99.0 \\
Extreme & 1 & 1.0 & 100.0 \\
\hline Total & 100 & 100.0 & \\
\hline
\end{tabular}


Table shows that 5 percent of respondents out of 100 had mild level of depression, 27 percent respondents experienced borderline clinical depression, Majority i.e. 61 percent had moderate level of depression, and 6 percent respondents had severe level of depression, while only 1 percent had extreme level of depression.

Table 4.2

Level of Depression among Respondents *Academic Level Cross Tabulation

\begin{tabular}{|c|c|c|c|c|c|c|}
\hline \multirow{2}{*}{$\begin{array}{c}\text { Level of } \\
\text { Depression }\end{array}$} & \multicolumn{5}{|c|}{ Academic level of Achievement } & \\
\hline & Low & Satisfactory & Medium & Very good & Exceptional & \\
\hline $\begin{array}{l}\text { Mild mood } \\
\text { disturbance }\end{array}$ & 0 & 0 & 0 & 2 & 3 & \\
\hline Borderline Dep. & 0 & 2 & 4 & 12 & 9 & \\
\hline Moderate & 45 & 6 & 2 & 4 & 4 & \\
\hline Severe & 5 & 1 & 0 & 0 & 0 & \\
\hline Extreme & 1 & 0 & 0 & 0 & 0 & \\
\hline Total & 52 & 9 & 6 & 18 & 16 & \\
\hline $\begin{array}{l}\quad \text { As is } \\
\text { students with } \mathrm{p} \\
\text { decreases signi } \\
\text { achievement an } \\
\text { Table } 4.3 \\
\text { Correlation bet }\end{array}$ & $\begin{array}{l}\text { vidence } \\
\text { hysical } \\
\text { ying a } \\
\text { d level c } \\
\text { veen } A c\end{array}$ & $\begin{array}{l}\text { from the } \\
\text { allenges inc } \\
\text { gative relati } \\
\text { depression. } \\
\text { demic Achie }\end{array}$ & $\begin{array}{l}\text { ove tabl } \\
\text { ase as th } \\
\text { betwee }\end{array}$ & $\begin{array}{l}\text { above, lev } \\
\text { academic } 1 \\
\text { he two va }\end{array}$ & $\begin{array}{l}\text { of de } \\
\text { el of a } \\
\text { ables i.e }\end{array}$ & \\
\hline & & & Academic I & evel & el of Depressic & \\
\hline $\begin{array}{l}\text { Academic } \\
\text { Level }\end{array}$ & $\begin{array}{l}\text { Pearson } \\
\text { Sig. (2-1 } \\
\text { N }\end{array}$ & $\begin{array}{l}\text { Oorrelation } \\
\text { iled) }\end{array}$ & 100 & & $\begin{array}{c}-.559^{* *} \\
.000 \\
100\end{array}$ & \\
\hline Level of & Pearson & orrelation & $-.559^{* *}$ & & 1 & \\
\hline Depression & $\begin{array}{l}\text { Sig. (2- } \\
N\end{array}$ & & $\begin{array}{c}.000 \\
100\end{array}$ & & 100 & \\
\hline
\end{tabular}

Correlation is significant at the 0.01 level (2-tailed).

Table shows that the probability of the Pearson correlation test statistic was $p=0.000$, less than the alpha level of significance of 0.05 the table also shows negative correction of (-.559) exists between depression and achievement signifying an inverse significant relationship.

Findings of study can be summarized as:

- There is varied evidence about the prevalence of depression among students with physical needs. Most of the times however, the depression levels fall in the range of borderline to moderate degrees. 
- There is a significant negative correlation between depression and academic achievement i.e. as the level of depression increases, the academic achievement is likely to fall.

\section{Discussion}

The present study indicates that there is a negative relation between the level of depression and the academic achievement of the students with physical disabilities. The findings of current study are concurrent with previous studies, e.g. Pavlakis \& Kaitelidou (2012) described distance learning as a source of intense stress for the students of OUC (Open University of Cyprus). Hurd \& Xiao (2010) stated that participants of distance learning programs, offered either totally or partially on line, experience intense negative emotions due to distance between them and their tutor as well as their fellow students, not to mention lack of extra-language elements (eye contact, posture, face expressions, gestures, etc.)

The non-formal system of education i.e. distance education as offered in Allama Iqbal Open University in Pakistan, has its own inbuilt limitations. Students heavily rely on the material provided to them and the subject success is stringently linked to assignments itself. In the absence of formal coaching the learners feel short of developing the required skills, causing uncertainty and limited authority. Morley (2010) found that without information and debriefing about the agenda, disabled students not only experience stress and anxiety, but also difficulty in preparing themselves for higher education. The present study is also indicative of similar elements that have served as contributing agents of depression.

Successful communication may it be formal, informal or depicts any other form may encourage participation, command following and ensure a suitable response. A better face to face communication may yield better understanding and describe the intended behavior in qualitative terms. One of a significant shortcoming of non-formal education system can be an unclear expectation described in terms of difficult language thus adding to the difficulties of students. Students with physical disabilities at times may face communicational challenges along with the physical challenges and are confronted with more challenges than usual. The finding of this study also falls in line with a previous study Malik, Noreen, Mahmood, Ismail, Iftikhar \& Khan (2003), in which it was revealed that students with communication disorders exhibited poor performance in terms of level of academic achievement especially in terms of language content areas. It further established that as the severity in communication challenges increased, the performance in terms of academic achievements corresponded as a negative correlate. 


\section{Conclusions}

As is evidence from the finding itself that incidence of depression is prevalent in students with physical challenges in relation to their respective nonformal system of education. In quantitative terms this level of depression ranges from mild to severe forms, however a moderate level was most prevalent among the group.

Further to it the level of depression has a significant direct negative correlation with the academic achievement for this group of students. It can be concluded that as the level of depression increases in such students the likelihood of a poor performance in academics is increases to a significant level.

\section{Recommendations}

1. Students with physical challenges are apt to develop additional hazards when it comes to learning itself. A more formal, traditional and interactive environment has more to offer for such students and may be offered as a choice.

2. As is evidenced in the study limited human interaction may serve as a key element for depression. Since limited interaction with teachers and peers is a hallmark of non-formal education, the likelihood of depression prevails in such interactions. In order to avoid such elements students with physical challenges be encouraged and offered placements in regular education system where they have more chances to interact and engage with peers and teacher as a daily routine. The same can be practiced by the use of educational technology. As the world is turning into a global village, the electronic and digital devices are in reach of an ordinary person. The use of this technology can actually reduce the impacts of distance and increase the participation by timely and purposeful engagements in teaching learning, thus reducing the likely hood of elements like anxiety, etc.

3. The study has identified border line to moderate degree of depression among the students with physical needs (table 3). Likewise, impacts of low grade achievement on the motivation of the students are well documented in literature. Academic success is a stronger predictor for future prospects and learning. Research has reflected many a times that poor grade achievers fall a prey to absenteeism, dropouts and reduced motivation, etc. In order to ensure a life-long learning in students with physical challenges it becomes a vital strategy to include students in educational activities while ensuring the principles of accommodation at the levels of assessment, instruction and evaluation. A formal system of education has more tendencies and flexibilities to address to the pertinent needs of such a population. The increased level of 
depression will in turn end up as a poorer academic effort and a vicious circle may be reached thus the entire effort of teaching and learning may go in vain. Keeping in view the above points the concept of offering formal educational system is reiterated.

4. Since the level of disability has been identified to have a link with the severity of depression and academic achievement (table 4), students with physical challenges need a continuous support in terms of medical and psychological rehabilitation services through the process of continued counseling. A formal assessment identifying the specific needs of a student with physical needs may be conducted at the time of enrollment in specific program to validate and ascertain the available options. Parents at times remain unaware of the individual needs of such students and may not address to the emerging scenarios in the life of a student with disability. An earlier assessment in turn will help concerned address to the needs in time and spirit. Similarly parental program focusing early detection of depression and anxiety may yield results if attempted to address to the needs of challenging students. It is pertinent that parental programs be developed for students in close collaboration with the teachers in non-formal modes of learning.

\section{References}

American Psychiatric Association. (2000). Mood Disorders. Diagnostic and Statistical Manual of Mental Disorders, fourth edition, pp. 369-382.

Anderson, T. \& Dron, J. (2011). Three generations of distance education pedagogy. International Review of Research in Open and Distance Learning, 12(3), 80-97. Retrieved on March 19, 2018 from: http://www.irrodl.org/index.php irrodl/article/view/890/1663

Beck, A.T., Ward, C. H., Mendelson, M., Mock, J., \& Erbaugh, J. (1961). An inventory for measuring depression. Archives of General Psychiatry, 4, $561-571$.

Conrad, D. (2005). Building and Maintaining Community in Cohort-Based Online Learning. Journal of Distance Education, 20(1), 1-20).

Dirkx, J. M. (2001). The power of feelings: Emotion, imagination, and the construction of meaning in adult learning. New Directions for Adult and Continuing Education, 89, 63-72. 
Disability Right Commission (DRC).(2002). Policy Statement on Social Care and Independent Living. Retrieved from http//www.drcb.org/campaigns/health.asp accessed on 11 April 2014.

Hara, N., \& Kling, R. (1999). Students' frustrations with a web-based distance education course. First Monday, 4(12). Retrieved April 15, 2002, from http://www.firstmonday.dk/issues/issue4_12/index.html

Hara, N., \& Kling, R. (2003). Students' distress with a web-based distance education course: An ethnographic study of participants' experiences. Turkish Online Journal of Distance Education, 4(2). Retrieved on December 9, 2010 from: http://tojde.anadolu.edu.tr/tojde10/articles/hara.htm

Hurd, S., \& Xiao, J. (2010). Anxiety \& Affective Control among Distance Language Learners in China \& the UK. RELC Journal, 41(2), 183-200. Retrieved on December 7, 2010. http://rel.sagepub.com/content/41/2/183.full.pdf + html

Malik, M. A., Noreen, H., Mahmood, A., Ismail, A., Iftikhar, N., \& Khan, M., (2003). Communication abilities as a correlate of academic achievement, Journal Riphah College of Rehabilitation Sciences, 5(2), 76-80.

Morley, L. (2010). Disabled Students in Higher Education in Ghana and Tanzania: Towards Equity and Participation. UK: University of Sussex.

O'Regan, K. (2003). Emotion and E-learning. Journal of Asynchronous Learning Networks, 7(3), (Retrieved on 3rd June 2005 from the World Wide Web: http://www.sloan-c.org/publications/jaln/v7n3/pdf/v7n3_oregan.pdf).

Pakistan Bureau of Statistics. (2017). Disabled Population by Nature of Disability Retrieved from http://www.pbs.gov.pk/content/disabledpopulation-nature-disability

Pavlakis, A. \& Kaitelidou, D. (2012). Burnout Syndrome in Students of a Distance Learning Program: The Open University of Cyprus Experience. European Journal of Open, Distance and E-learning 
Riddell, S., Wilson, A., \& Tinklin, T. (2002). Disability and the Wider Access Agenda: Supporting Disabled Students in Different Institutional Contexts, Widening Participation and Lifelong Learning, 4, 12-26.

Riddell, S., Tinklin, T. \& Wilson, A., (2005). Disabled Students in Higher Education: Perspective in Widening Access and Changing Policy. London: Routledge Falmer.

Rovai, A. P., Wighting, M. J., \& Lucking, R. (2004). The classroom and school community. The Quarterly Review of Distance Education, 6(4),

U.S Census Bureau (2011). US \& World Population Clocks. Retrieved from http//www.census.gov/population/popclockworld.html Accessed 23 January 2018.

World Health Organization (2011) 10 Facts on Disability. Retrieved from $\mathrm{http} / / \mathrm{www}$.who.int/features/factfiles/disability/en/www.dailymail.co.uk/n ews/arti cle-2366260 Accessed on $21^{\text {st }}$ March 2018 